\title{
Japanese earthquake tests disaster warning networks
}

Tokyo. Last week's major earthquake off the northern tip of Japan exposed both the strengths and weaknesses of Japan's system for preventing disasters in the aftermath of such events. Tsunami warnings were broadcast on television with impressive speed, and some accurate predictions were made. But information on the earthquake itself, which measured 7.9 on the Richter scale, was slower to emerge, and some of the information was inaccurate and misleading.

In Tokyo, where the earthquake was felt quite strongly despite being nearly 1,000 $\mathrm{km}$ from the epicentre (see map), the ground had barely stopped rumbling when television stations broke into their broadcasts to issue tsunami warnings.

Roughly five minutes after the earthquake, which struck at 10:23 p.m. local time, Japan Broadcasting Corporation (NHK) transmitted a map of Japan with the Pacific coast of the northern island of Hokkaido flashing in red to indicate a 'tsunami warning', and the Pacific coast of the main island of Honshu flashing yellow as far south as Tokyo to indicate 'tsunami caution' (a lower level of warning).

These represent the first two of a threelevel warning system issued by the Japan Meteorological Agency (JMA). The third level of warning, 'great tsunami', indicates tsunami of a height of more than 3 metres.

The visual displays were accompanied by warnings in Japanese and English that residents on the Pacific coast of Hokkaido should flee to higher ground because tsunami "up to 2 metres high" might strike.

A few minutes later, the first predictions from JMA of times of arrival of tsunami were announced on NHK, with the earliest arrivals set at 11 p.m. (local time) for the northern tip of Hokkaido, 37 minutes after the earthquake. The first tsunami actually hit Nemuro on the northern tip of Hokkaido at 10.58 p.m. and was 1.73 metres high.

But after this initial success, things began to degenerate. At 11.34 p.m., more than an hour after the earthquake, the JMA upgraded its warning for the northern Pacific coast of Honshu to a tsunami warning rather than caution. JMA say they did this because of "the situation in Hokkaido". But this caused confusion among disaster prevention officials.

Under a tsunami caution, officials must go to the coast to observe the tsunami. Under a tsunami warning, where the tidal wave can be up to about 2 metres high, they must flee away from the coast. Some officials who followed the rules and went to the northern coast of Honshu under the tsunami caution, apparently did not get to hear the second upgraded warning one hour later. If a big tsunami had come, says one critic, "they would have been zapped".

Broadcasts of information on the earthquake itself were even less impressive. The tsunami warnings began at 10.28 p.m., only five minutes after the earthquake. But they were not accompanied by any information about the earthquake itself, and television

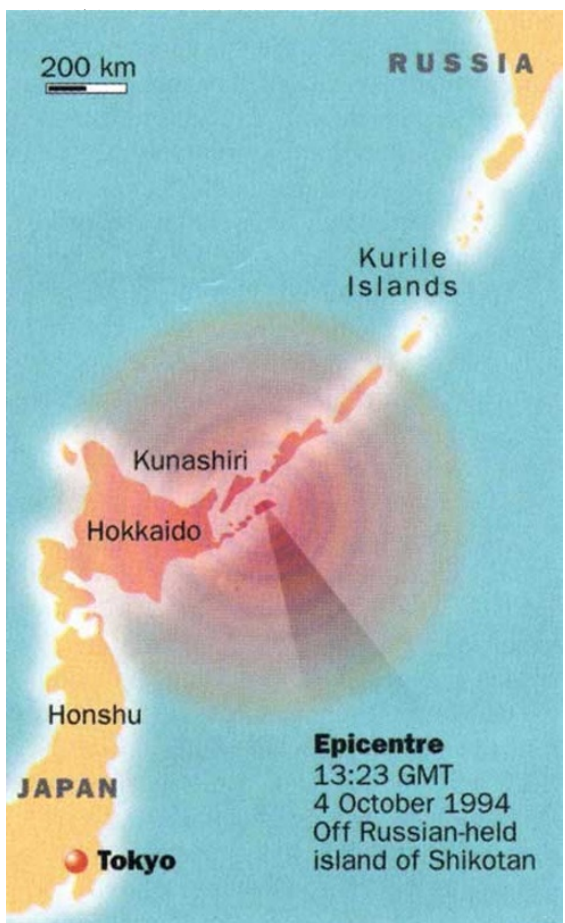

viewers were left ignorant of where the earthquake occurred, or how large it was.

The first information on the size of the earthquake from JMA came several minutes later. It gave the magnitude of the earthquake in various cities on the Japanese scale of one (minor rumbling) to seven (a major disaster). The high readings, of up to six, were centred in northern Hokkaido.

Disaster prevention officials complain that such information is just as important as tsunami warnings for responding to an earthquake, and are calling on JMA to release it quicker. In response, JMA announced a few days later that, as from next March, it will announce the magnitude of earthquakes about two minutes after they occur, before the release of tsunami warnings.

Earlier this year, the agency added about 150 unmanned stations around the country for measuring the effects of earthquakes. But it has yet to organize this system to issue very fast measurements. From March next year, JMA says it will issue the highest readings for a given region, rather than waiting for all measurements from each region, within about 2 minutes of an earthquake.

\section{Former Italian minister accused over space funds}

Munich. Sandro Fontana, Italy's former minister of research, has become the latest addition to the list of individuals indicted over the mismanagement of funds belonging to the Italian Space Agency (ASI).

Fontana, who was minister from July 1992 to August 1993, joins ASI's former president Luciano Guerriero and his board of directors, who were indicted in November last year partly on the charge that they had deliberately diverted funds away from basic research.

According to ASI's own rules, 15 per cent of its budget should be reserved for basic research. But three years ago a conflict between Guerriero and Remo Ruffini, chairman of ASI's science committee, which assesses research grant applications, over whether the 15 per cent should include contributions to the basic research activities of the European Space Agency (ESA), brought the agency to a virtual standstill (see Nature 356, 647; 1992).

To break the impasse, Fontana established a committee of five 'wise men' in February last year to investigate this issue and possible corruption in assigning contracts for ASI's controversial X-ray satellite SAX, which has still not been launched (see Nature 366, 101; 1994). Fontana gave the committee only one month to carry out its investigations, and then accepted its conclusion that there had been no wrongdoing at ASI, and that Guerriero's interpretation of the 15 per cent was correct.

The Court of Accounts has now ruled that Fontana should not have accepted the hastily completed report of the committee, which it considers to be flawed. It also says that Guerriero misled the committee by falsely interpreting a letter from JeanMarie Luton, director-general of the ESA, as indicating that almost a fifth of Italy's 602 billion lire (US\$385 million) contribution to ESA in 1993 was spent on basic research.

Fontana, Guerriero and his board of directors have 30 days in which to reply to charges of mismanaging ASI's funds. If they are unable to provide the Court of Accounts with a satisfactory explanation, the court can decide either to impose a fine or to pass the case on to criminal courts to take legal action against those accused.

Meanwhile ASI itself is re-emerging from its period of political turmoil. Only one of those indicted is associated with ASI today (Enrico Cerrai is still a member of the board). A new board, under the chairmanship of Giorgio Fiocco, atmospheric physicist, was installed by Colombo in February this year, and Fiocco appointed a new scientific committee last month

Alison Abbott 